\title{
Governança Corporativa nos Fundos de Investimento Imobiliário: Mudanças após Instrução CVM n 571/2016
}

\author{
Corporate Governance in Real Estate Investment Funds: Changes after CVM \\ instruction edition $n^{0}$ 571/2016
}

\section{Gobierno Corporativo en Fondos de Inversión Inmobiliaria: Cambios después de la Instrucción CVM n⿳ 571/2016}

José Orcélio do Nascimento Docente de especialização mercado de capitais: FECAP/SP jorcelio@uol.com.br http://lattes.cnpq.br/0227311737052534 http://orcid.org/0000-0002-1790-1863

Lígia Maria Verna Stefanini ${ }^{1}$ Discente de especialização mercado de capitais: FECAP/SP verna.ligia@gmail.com http://lattes.cnpq.br/8842312119615384 http://orcid.org/0000-0001-5216-8962

Érica de Fátima Soares ${ }^{1}$ Discente de especialização mercado de capitais: FECAP/SP erica_soares86@hotmail.com http://lattes.cnpq.br/0384237750514917 https://orcid.org/0000-0002-4372-3829

Leonardo Fabris Lugoboni ${ }^{2}$ Docente de mestrado em administração: UNIB/SP leo_fabris@hotmail.com http://lattes.cnpq.br/3762938281211058 https://orcid.org/0000-0003-1396-9681

Michele Braga dos Santos Silva Discente de mestrado em administração: FMU/SP michelebraga06@hotmail.com http://lattes.cnpq.br/0696322751021600 http://orcid.org/0000-0002-8823-7533

Marcus Vinicius Moreira Zittei ${ }^{3}$ Docente de mestrado em administração: FMU/SP marcuszittei@zittei.com.br http://lattes.cnpq.br/7947828317635699 http://orcid.org/0000-0001-8398-6941

Fundação Escola de Comércio Álvares Penteado, FECAP, Brasil ${ }^{1}$ Universidade Ibirapuera, UNIB, Brasil ${ }^{2}$ Centro Universitário das Faculdades Metropolitanas Unidas, FMU, Brasil ${ }^{3}$

Artigo recebido em 08.04.2019. Última versão recebida em 29.08.2019. Aprovado em 30.08.2019. 
Governança corporativa nos fundos de investimento imobiliário: mudanças após instrução CVM nº 571/2016

\title{
Resumo
}

Os fundos de investimento imobiliário têm como público alvo majoritariamente pessoas físicas, as quais devem ser providas de informações suficientes para balizar suas decisões de investimento. Tendo em vista a edição da Instrução CVM n ${ }^{\circ} 571 / 2016$, a qual proporcionou avanço para a indústria destes fundos, este trabalho tem como objetivo demonstrar os impactos na governança de fundos de investimento imobiliário decorrentes da edição da Instrução CVM no 571/16, que altera a Instrução CVM no 472/08. Foi realizada uma pesquisa qualitativa descritiva mediante pesquisa documental. Os resultados evidenciaram que as diversas alterações ocorridas na regulamentação desde 2011, foram incorporadas na governança corporativa dos fundos de investimento imobiliário, portanto, sua evolução em comparação à legislação anterior.

Palavras-chave: Fundo de Investimento Imobiliário. Governança Corporativa. Instrução $\mathrm{CVM} \mathrm{n}^{\circ}$ 571/2016.

\section{Corporate Governance in Real Estate Investment Funds: Changes after CVM instruction edition $n^{0}$ 571/2016}

\begin{abstract}
Real estate investment funds are primarily targeted at individuals, who must be provided with sufficient information to make their investment decisions. In view of the edition of CVM Instruction $\mathrm{n}^{\circ} 571 / 2016$, which provided an advance to the industry of these funds, this work aims to demonstrate the impacts on the governance of real estate investment funds resulting from the edition of CVM Instruction $n^{\circ}$ 571/16, which alters the CVM Instruction $n^{\circ} 472 / 08$. Descriptive qualitative research was conducted through documentary research. The results showed that the various changes in the regulation since 2011 were incorporated into the corporate governance of the real estate investment funds, therefore its evolution compared to the previous legislation.
\end{abstract}

Keywords: Real Estate Investment Fund. Corporate Governance. CVM Instruction $\mathrm{n}^{\circ}$ $571 / 2016$.

\section{Gobierno Corporativo en Fondos de Inversión Inmobiliaria: Cambios después de la Instrucción CVM no 571/2016}

\section{Resumen}

Los fondos de inversión inmobiliaria están dirigidos principalmente a personas, a las que se les debe proporcionar información suficiente para tomar sus decisiones de inversión. En vista de la edición de la Instrucción $n^{\circ} 571 / 2016$ de la CVM, que adelantó a la industria de estos fondos este trabajo tiene por objeto demostrar los impactos en la gobernanza de los fondos de inversión inmobiliaria resultantes de la edición de la Instrucción $\mathrm{n}^{\circ}$ 571/16 de la CVM, eso altera el CVM Instrucción $n^{\circ}$ 472/08. Se llevó a cabo una investigación cualitativa descriptiva a través de la investigación documental. Los resultados mostraron que los diversos cambios en el reglamento desde 2011 se incorporaron al gobierno corporativo de los fondos de inversión inmobiliaria, por lo tanto, su evolución en comparación con la legislación anterior. 
Governança corporativa nos fundos de investimento imobiliário: mudanças após instrução CVM nº 571/2016

Palabras clave: Fondo de Inversión Inmobiliaria. Gobierno Corporativo. Instrucción CVM n ${ }^{\circ}$ $571 / 2016$. 


\section{INTRODUÇÃO}

Os Fundos de Investimento Imobiliário (FII) registraram, nos últimos anos, aumento considerável no volume de negócios no mercado secundário de cotas, atraindo investidores de varejo, sobretudo pelos benefícios proporcionados, entre eles, a isenção de imposto de renda (Comissão de Valores Mobiliários [CVM], 2015). Pela perspectiva do investidor, os FII se tornaram uma opção de investimento atraente, principalmente por estar atrelado a um imóvel, sendo o crescimento do mercado imobiliário no Brasil um grande incentivador (Steffen, 2015).

Diante da disseminação do citado veículo de investimento às pessoas físicas e cada vez mais observado o incremento nos registros de negociação, a transparência nas informações divulgadas pelos FII, assim como a diligência do administrador com a qualidade e periodicidade na publicação dos documentos, se tornam imprescindíveis para completar uma governança corporativa sustentável neste tipo de produto (Ferreira, 2011).

A Comissão de Valores Mobiliários, neste contexto, promoveu em 2015, alterações no normativo que trata sobre a constituição e funcionamento dos FII (Instrução CVM n ${ }^{\circ}$ 472/08). $\mathrm{O}$ escopo principal da alteração foi proporcionar aprimoramentos no que diz respeito à divulgação de informações periódicas e eventuais pelos administradores de FII e promover aperfeiçoamento nas questões ligadas à governança (CVM, 2015).

Este trabalho tem como objetivo demonstrar os impactos na governança de fundos de investimento imobiliário decorrentes da edição da Instrução CVM nº 571/16, alteradora da Instrução CVM n ${ }^{\circ}$ 472/08.

A expansão da oferta de novos FII nos anos recentes, bem como o crescente interesse de investidores individuais e institucionais por esse mercado vem a alicerçar a relevância das pesquisas sobre o tema (Moraes, 2016).

O estudo se justifica pela relevância de se entender que os FII são veículos de investimento que acolhem investidores de varejo que precisam da transparência das informações.

\section{REFERENCIAL TEÓRICO}

\subsection{Fundos de Investimento Imobiliário}

Os Fundos de Investimentos Imobiliários (FII) foram criados pela Lei 8.668/93 a qual dispõe sobre sua constituição e seu regime tributário. Atualmente, os FII são regulamentados pela Instrução CVM no 472/08, a qual sofreu diversas alterações pelas Instruções $n^{\circ} 478 / 09, n^{\circ}$ $498 / 11, n^{\circ} 517 / 11, n^{\circ} 528 / 12, n^{\circ} 554 / 14$ e, recentemente alterada, significativamente, pelas Instruções $n^{\circ} 571 / 16$ e $n^{\circ} 580 / 16$.

O FII permite a composição de uma carteira de empreendimentos imobiliários, os quais, pelo volume de recursos envolvidos para sua formação ou aquisição, não estariam ao alcance de investidores individuais (Ferreira, 2011).

Os FII foram criados com base no Real Estate Investment Trust (REIT) americanos e se tornaram alternativa de investimento para gestores de recursos e investidores em geral, sobretudo em decorrência da crescente indústria brasileira (Moraes, 2016). 
Governança corporativa nos fundos de investimento imobiliário: mudanças após instrução CVM nº 571/2016

Os REITS ofereciam aos investidores, mormente aos pequenos, a oportunidade do investimento no setor imobiliário com custos reduzidos e gestão profissional, de modo que desembolsavam menos dinheiro para investir em grandes corporações (Sato, 2008).

Assim como os REIT, os FII surgiram no Brasil com o objetivo de acumular grandes volumes de recursos para investimento no setor de Real Estate, caracterizado pelos ativos de alto valor, baixa liquidez e longo período de retorno (Brito \& Alencar, 2016).

De acordo com a Instrução 472/08, FII são constituídos como condomínios fechados e não possibilitam aos seus investidores o resgate de suas cotas a qualquer momento, mas tão somente ao final de seu prazo de duração ou então se deliberado por sua liquidação antecipadamente por consenso da assembleia geral de cotistas.

\subsection{Instrução CVM No 472 e sua Alterações}

As alterações na regulamentação do mercado de FII foram motivadas pela situação econômica vivida no Brasil nos anos 2000, que levou ao crescimento de emprego e de renda da população, sendo estes alguns dos motivos que influenciaram o crescimento do mercado imobiliário (Steffen, 2015).

Em 2015 a CVM realizou audiência pública para promover alterações na Instrução no 472/08 visando a melhoria da regulamentação quanto a divulgação de informações periódicas e eventuais pelos administradores de FII, bem como governança dos fundos.

A CVM recebeu número expressivo de sugestões e reclamações de investidores, em sua maioria pessoas físicas, que enfatizaram ter tido seu direito cerceado por alguns administradores e também citaram atrasos na divulgação de informações (Ferrari, 2016).

Sobre a divulgação de informações, Okazuka (2015) relata que os administradores têm o dever de realizar diversas publicações periódicas sobre os seus objetivos, os investimentos realizados, perspectivas do mercado, situação das carteiras dos fundos, processos judiciais, o que em muito se assemelha a companhias abertas.

A CVM determina que as instituições ofertantes busquem uma ampla divulgação das informações, produzindo materiais publicitários com uma linguagem "serena e moderada" e se responsabilizando pela veracidade de todo o conteúdo (Okazuka, 2015).

\subsection{Governança Corporativa}

A governança corporativa teve sua origem no século 20. Em vários países, grandes empresas tiveram amplo crescimento financeiro em uma escala global, resultando em uma restruturação da estrutura de controle, visando o interesse de todos os sócios e principalmente da empresa. A vertente mais aceita é que a Governança Corporativa surgiu para superar o conflito de agência, tentando evitar ao máximo o interesse de apenas um, e cuidando ao máximo de todo o conjunto empresarial e de todos os sócios. (Instituto Brasileiro de Governança Corporativa [IBGC], 2017).

Segundo Silveira (2002), a necessidade de novos recursos ao menor custo motivou as empresas brasileiras a adotarem novas práticas de governança, principalmente no que diz 
Governança corporativa nos fundos de investimento imobiliário: mudanças após instrução CVM nº 571/2016

respeito à transparência das informações ao mercado, direitos dos minoritários e profissionalização do Conselho de Administração.

Atualmente, os investidores de fundos imobiliários passam cada vez mais a buscar um acompanhamento mais próximo dos investimentos. Pelas características dos fundos, o papel dos investidores está bem próximo aos de minoritários em uma companhia aberta (Okazuka, 2015).

A adoção das práticas de governança corporativa gera benefícios para todas as partes: investidores, empresas e mercado acionário. Para os investidores, há maior precisão na precificação dos ativos, redução de risco, maior fiscalização e transparência das informações. Para as empresas há impacto em sua imagem institucional, valorização e maior demanda de suas ações bem como menor custo de capital. Para o mercado acionário, os benefícios estão ligados à liquidez dos ativos, aumento de recurso para empresas e novas emissões de ativos pelas empresas (Ferreira, 2011).

A governança corporativa, portanto, vem transformando o mercado, tornando as empresas mais atrativas para os investidores. As empresas que possuem boas práticas demonstram, aos olhos dos investidores, maior capacidade de influência, maior transparência nas informações, imparcialidade nas tomadas de decisões e controle de conflito de interesses (Ferreira, 2011).

\section{PROCEDIMENTO METODOLÓGICO}

O presente trabalho tem como norteador o estudo realizado por Ferreira (2011), que avaliou as características de Governança Corporativa do FII.

O estudo de Ferreira (2011) considerou as alterações ocorridas na regulamentação e na documentação dos FII da época em que foi desenvolvida (2011) e buscou identificar o novo posicionamento do FII no mercado, se ele se tornou mais flexível, ativo e consequentemente atrativo. A pesquisa da Ferrari (2016) envolveu a compreensão dos conceitos e critérios de governança corporativa e como eles podem se relacionar com a estrutura e operação dos FII, comparando-os com outros ambientes de investimento, FIP e SA.

Os critérios utilizados no presente estudo são os mesmos do estudo de Ferreira (2011). Foi realizada análise da documentação e da regulamentação e suas alterações, buscando identificar se houve ou não aprimoramento da governança corporativa nos FII após a edição da Instrução CVM n ${ }^{\circ}$ 571/16. A comparação, porém, foi restrita aos FII. Os resultados obtidos por Ferreira (2011) e no presente trabalho foram dispostos em uma matriz de comparação, buscando identificar os itens que coincidiam.

Foi realizada uma pesquisa descritiva, por meio da qual foi possível traçar as alterações sofridas pela Instrução CVM nº 472/08.

Segundo Gil, (2010) pesquisas descritivas têm como objetivo principal a descrição das características de determinada população ou fenômeno ou o estabelecimento de relações entre variáveis.

Foi replicada a pesquisa de Ferreira (2011), a fim de verificar o aprimoramento da governança corporativa pós edição da Instrução CVM nº 571/2016. 
Governança corporativa nos fundos de investimento imobiliário: mudanças após instrução CVM nº 571/2016

Os FII selecionados para análise são os fundos utilizados na pesquisa de Ferrari (2016): HG Real Estate Fundo de Investimento Imobiliário, BC Fund de Fundos de Investimentos Imobiliário, Fundo de Investimento Imobiliário Shopping Pátio Higienópolis, Fundo de Investimento Imobiliário Continental Square Faria Lima e Kinea Renda Imobiliária Fundo de Investimento Imobiliário.

Quanto aos procedimentos desta pesquisa é, documental. Segundo Gil (2010), a diferença entre a pesquisa bibliográfica e a documental é que esta última se vale de materiais que ainda não receberam ainda um tratamento analítico, ou que ainda podem ser reelaborados de acordo com os objetivos da pesquisa.

\section{RESULTADOS E ANÁLISES}

\subsection{Identificação dos Critérios}

Para realização da comparação e atualização da pesquisa desenvolvida por Ferreira (2011), foram levados em conta os mesmos critérios por ela utilizados: itens relevantes, para demonstração da evolução da governança; itens comuns aos instrumentos de investimento, para verificação da aderência ou não do instrumento à governança corporativa e itens capazes de permitir as evidências necessárias para, eventualmente, propor alterações ao resultado alcançado. Ferrari (2016) optou por selecionar os itens mais comuns e principalmente os que mais apresentavam a capacidade de mensurar a governança no ambiente de investimento FII. Tais critérios de governança escolhidos por Ferreira (2011) foram ora reproduzidos na matriz de comparação, para realização da presente pesquisa, demonstrando os resultados por ela obtidos e os coletados com o presente estudo.

Para manter a sistemática da comparação com o trabalho de Ferrari (2016), o presente levantamento também foi dividido em duas etapas, com base na fonte de dados utilizada: Regulamentação e Documentação, estas subdivididas nos ambientes de investimento, em análise e de comparação, com a inclusão de coluna que permite comparar o trabalho replicado com o presente trabalho.

No item Regulamentação, foi analisada as instruções CVM $n^{\circ} 472 / 2008$ e sua recente alteração a instrução CVM n ${ }^{\circ}$ 571/2016, que regula os fundos de investimento imobiliário.

No item Documentação, foram analisados os documentos (prospectos, regulamentos, atas e outras comunicações) dos seguintes FIIs: HG Real Estate Fundo de Investimento Imobiliário (regulamento datado de 13/10/2016), BC Fund de Fundos de Investimentos Imobiliário (regulamento datado de 14/12/2016), Fundo de Investimento Imobiliário Shopping Pátio Higienópolis (regulamento datado de 14/03/2016), Fundo de Investimento Imobiliário Continental Square Faria Lima (regulamento datado de 27/09/2016) e Kinea Renda Imobiliária Fundo de Investimento Imobiliário (regulamento datado de 25/04/2017). 


\subsection{Síntese da Regulamentação e Análise Comparada}

Tabela 1

\section{Propriedade}

\section{PROPRIEDADE}

\section{FERREIRA - 2011}

O quotista não exerce qualquer direito sobre os imóveis que pertencem ao

Direito de Propriedade

fundo. A responsabilidade sobre a gestão dos ativos é do administrador do fundo.

Direito a voto

Regras de Assembleia (convocação e pauta)

Votação em Assembleia

Equidade no Tratamento
Os quotistas têm direito a voto através da assembleia geral de quotistas. Cada quota corresponde a um voto.

A convocação de assembleia deve ocorrer com antecedência e deve indicar todos os assuntos a serem discutidos.

A maioria dos itens depende da aprovação de quotistas que representem metade, no mínimo, das quotas emitidas, com exceção para alteração de regulamento, fusão, incorporação, cisão ou transformação e apreciação de laudo de avaliação de bens e direitos integralizados, que devem utilizar quórum específico definido em regulamento.

Os quotistas são tratados de maneira igualitária.
DADOS DA PESQUISA - 2017 RESULTADO DA COMPARAÇÃO
Sem alteração
Sem alteração

Sem alteração

A primeira convocação das assembleias deve ocorrer com antecedência mínima e todos os assuntos e documentos devem estar disponíveis para consulta aos

interessados no mesmo dia da convocação. Previsão de inclusão de assuntos na ordem do dia por cotistas ou representante de cotistas.

As deliberações da assembleia geral serão tomadas por maioria de votos dos cotistas presentes. Matérias mais sensíveis

dependem da aprovação por maioria de votos dos cotistas presentes e que representem: $25 \%$, das cotas emitidas, quando o fundo tiver mais de 100 cotistas ou metade, no mínimo, das cotas emitidas, quando o fundo tiver até 100 cotistas.

Tratamento igualitário pode haver direito de preferência na subscrição de novas quotas, de acordo com o previsto no
Alteração do $\$ 1^{\circ}$ do artigo 20 , prevendo quóruns mais específicos, baseados na representatividade das cotas emitidas e do número de cotistas que o fundo possui. Rol de matérias que exige quórum qualificado aumentou.

Inclusão do artigo 24, que prevê que o voto do cotista deve ser exercido no interesse do fundo e inclusão dos incisos V e VI no $\$ 1^{\circ}$ do art. 24, referente vedações ao direito de voto.

Inclusão do $\$ 3^{\circ}$ no artigo 19 com prazos mínimos de antecedência para convocação das assembleias, inclusão do artigo 19-A com rol mínimo de documentos a serem disponibilizados e inclusão da obrigatoriedade da proposta da administração para assembleias gerais extraordinárias (art. 41. I) Inclusão de assuntos na ordem do dia (artigo $19, \S 4^{\circ}$ )

Inclusão do $\S 1^{\circ}$ do artigo 15 para concessão obrigatória do direito de preferência nos casos em que o administrador emitir cotas sem autorização prévia da assembleia.

UFAMBR, Manaus, v. 1, n.2, art. 1, pp. 01-27, julho-dezembro, 2019 http://www.periodicos.ufam.edu.br/ufambr 
Governança corporativa nos fundos de investimento imobiliário: mudanças após instrução CVM no 571/2016

regulamento de cada fundo.

ANÁLISE FERREIRA 2011

ANÁLISE PESQUISA 2017

Nota: Dados da pesquisa
No tema Propriedade, a partir da Regulamentação, é possível identificar que a forma de propriedade é indireta. No FII assim como no FIP e na SA, o quotista não exerce direito sobre os imóveis ou ativos pertencentes ao fundo. A administração dos ativos é responsabilidade da administradora assim como no FIP e do Conselho de Administração no caso da SA. Portanto a gestão dos ativos neste modelo de propriedade é distante do investidor. O poder de decisão fica limitado e exercido via votação em Assembleias, proporcionalmente o número de votos ao número de quotas. A votação em assembleia tem os quóruns determinados em regulamento, sendo sempre mais restrito para assuntos mais relevantes. Para os ambientes de investimento de comparação, conceitos de votação semelhantes são utilizados.

No tema Propriedade, a partir da Regulamentação, foi possível constatar alterações referentes: direito e vedações ao voto, regras de assembleia (prazos de convocação, disponibilização de documentos e possibilidade de assuntos na ordem do dia, quóruns diferenciados para assuntos mais sensíveis, baseado na representatividade das cotas emitidas e do numero de cotistas, incremento do rol de matérias que exigem quóruns qualificados e inclusão de dispositivo que proporciona a equidade no tratamento dos cotistas.

Tabela 2

\section{Conselho de Administração}

\section{CONSELHO DE ADMINISTRAÇÃO \\ Composição do} Conselho

Relacionamento

Atribuições do

Conselho -

Estratégia de

Investimento
FERREIRA - 2011

Não existe a figura do Conselho de Administração.

\section{Não identificado.}

A estratégia de investimento está determinada em regulamento e pode sofrer alteração a partir de votação em assembleia. O administrador do fundo deve: selecionar os bens e direitos que comporão o patrimônio do fundo, desacordo com a política de investimento prevista no respectivo regulamento. A participação do fundo em empreendimentos imobiliários poderá ocorrer por meio da aquisição de quaisquer direitos reais sobre bens imóveis; ações, debêntures,

bônus de subscrição, direitos, recibos de subscrição e certificados de desdobramentos, certificados de depósito de valores mobiliários, cédulas de debêntures, quotas de fundos de investimento, notas promissórias e quaisquer outros valores mobiliários, desde que se trate de emissores cujas atividades preponderantes sejam permitidas aos FII; ações ou quotas de sociedades cujo único propósito se enquadre entre as atividades permitidas aos FII; quotas de fundos de

investimento em participações (FIP) ou de fundos de investimento em
DADOS DA PESQUISA - 2017

Sem alteração.

Não identificado. A participação do fundo em empreendimentos imobiliários poderá se dar por meio da aquisição dos ativos descritos no art. 45. Inclusão das letras imobiliárias

garantidas como ativo que poderá integrar o patrimônio do fundo. Previsão de prévia avaliação também pelo administrador (e não só pelo gestor e terceiro independente como antes constava) quando da aquisição de imóveis, bens e direitos de uso a serem adquiridos pelo fundo. Possibilidade de aquisição de imóveis gravados com ônus reais e necessidade de indicação da localização geográfica das áreas em que o
fundo pode adquirir imóveis ou direitos a eles fundo pode adquirir imóveis ou direitos a eles

\section{RESULTADO DA COMPARAÇÃO}

Sem alteração.

Sem alteração

Inclusão do inciso X no art. 45 (letras imobiliárias garantidas) Alteração do $\S 4^{\circ}$ do art. 45 para prever que a avaliação dos imóveis, bens e direitos de uso a serem adquiridos pelo fundo devem ser objeto de prévia avaliação também pelo administrador (e não só pelo gestor e terceiro independente como antes

constava). Inclusão de dispositivos obrigatórios que devem constam no regulamento do fundo: Possibilidade de aquisição de imóveis gravados com ônus reais (art., 15, II, e) e necessidade de localização geográfica das áreas em que o fundo pode adquirir imóveis ou direitos a eles relacionados, se aplicável; (art., 15, II, f)

UFAMBR, Manaus, v. 1, n.2, art. 1, pp. 01-27, julho-dezembro, 2019 http://www.periodicos.ufam.edu.br/ufambr 
ações que sejam setoriais e que invistam exclusivamente em construção civil ou no mercado imobiliário; certificados de potencial adicional de construção; quotas de outros FII; certificados de recebíveis imobiliários e quotas de fundos de investimento em direitos creditórios (FIDC) que tenham como política de investimento, exclusivamente, atividades permitidas aos FII letras hipotecárias; e letras de crédito imobiliário.

O regulamento pode prever a subscrição parcial das quotas

Atribuições do Conselho - Captação de Recursos representativas do patrimônio do fundo, bem como o cancelamento do saldo não colocado. Ele pode manter parcela do seu patrimônio permanentemente aplicada em quotas de fundos de investimento ou títulos de renda fixa, públicos ou privados, para atender suas necessidades de liquidez. relacionados, se aplicável.

O regulamento poderá autorizar a subscrição parcial das cotas representativas do patrimônio do fundo, bem como o cancelamento do saldo não colocado. Com relação à aplicação do patrimônio do fundo, sem alterações. O regulamento do fundo deve prever sobre (i) a possibilidade de aquisição

de imóveis gravados com ônus reais, (ii) sobre a localização geográfica das áreas em que o fundo pode adquirir imóveis ou direitos a eles relacionados, se aplicável, (iii) sobre a possibilidade ou não de futuras emissões de cotas, e se for o caso sobre a autorização para a emissão de novas cotas a critério do

administrador, independentemente de aprovação em assembleia geral e de alteração do regulamento.
Alteração do art. 13 para "autorizar" a subscrição parcial das cotas e não "prever" como constava. Alteração do art. 15 para inclusão dos itens "e" "f", no inciso II e alteração do inciso VIII do mesmo artigo.
ANÁLISE

FERREIRA - 2011

ANÁLISE

PESQUISA - 2017
No FII não existe o Conselho de Administração, no FIP esta figura estratégica é feira pelo Comitê de Investimentos. No FII a direção geral dos negócios, estratégia e administração estão prevista em regulamento e qualquer alteração dependerá da aprovação da assembleia geral de quotistas. Este conceito de alteração é muito rígido, dificilmente alterações destes itens serão feitas, porque dependem da aprovação restrita da assembleia, em casos de FII pulverizados, que são maioria, a aprovação é inviável. Este tipo de situação protege o investidor porque impede que ações sejam tomadas sem seu consentimento, porém impede que oportunidades possam ser aproveitadas. A captação de recursos assim como o direcionamento dos investimentos, está previsto em regulamento e alterações dependem da assembleia. A alteração que prevê a subscrição parcial de quotas auxilia no lançamento de novos FII, porque é possível montar operações maiores sem necessidade de desistência caso às captações não correspondam às expectativas. Neste ponto o FIP tem um volume pré-determinado, que o investidor conhece no momento do investimento. Na SA é possível realizar novas emissões de ações com maior facilidade e frequência, porém também depende de aprovação da assembleia caso não previsto no estatuto.

A rigidez para realização de alterações no regulamento, antes verificadas, foi flexibilizada e recebeu novos critérios na nova instrução. Disto resultou em novas oportunidades para captação de recursos, seja por deliberação da assembleia, cujos quóruns foram ajustados para facilitar as aprovações, seja pelas emissões aprovadas a critério do administrador, a exemplo do que ocorre com as companhias com o capital autorizado. 
Tabela 3

\section{Regras de Distribuição e Dispersão}

\section{REGRAS DE}

DISTRIBUIÇÃO E

DISPERSÃO

\section{Liquidez}

Dispersão

ANÁLISE

FERREIRA - 2011

ANÁLISE

PESQUISA - 2017

Fonte: Dados da pesquisa

\section{Tabela 4}

Gestão

$$
\text { GESTÃO }
$$

RESULTADO DA COMPARAÇÃO

Não foram identificados itens previstos em regulamentação visando garantir a

$$
\text { liquidez das quotas ou ações. }
$$

Sem alteração

Sem alteração

O líder da distribuição organizará plano de distribuição, que poderá levar em conta suas relações com clientes e outras considerações de natureza comercial ou estratégica. Pode ser constituído FII destinado exclusivamente a investidores qualificados, pode dentre outros itens: prever a existência de quotas com direitos ou características especiais quanto à ordem de preferência no pagamento dos rendimentos periódicos.

O FII pode ser destinado apenas a investidores qualificados, mas na maioria dos casos não é. O investidor, sócio ou construtor do empreendimento imobiliário investido não pode adquirir mais de $25 \%$ das quotas emitidas pelo fundo, caso contrário ocorrerá perda da isenção fiscal para o fundo. No existem regras nos FII para impedir que exista concentração de quotas em um único quotista, o que representa um risco no investimento.

A questão da concentração das cotas do fundo nas mãos de poucos cotistas, apresentada pela Fernanda, após a alteração promovida na ICVM 472 permaneceu, Não houve alterações na legislação para inibir tais práticas, sendo que os motivos para tanto podem estar associados à própria dinâmica do mercado de capitais e das características do produto FII.

COMPOSIÇÃ̃O DA GESTẪO
Serão geridos por instituição administradora autorizada pela CVM, que deverá ser exclusivamente instituição

financeira.
DADOS DA PESQUISA - 2017

RESULTADO DA COMPARAÇ̃̃O
Sem alteração

Sem alteração 
Governança corporativa nos fundos de investimento imobiliário: mudanças após instrução CVM nº 571/2016

Compete ao administrador realizar todas as operações e

FUNCÕES DA ADMINISTRADORA

INFORMAÇÕES

\section{ANÁLISE}

FERREIRA - 2011

ANÁLISE PESQUISA - 2017 praticar todos os atos que se relacionem com o objeto do fundo; exercer todos os direitos inerentes à propriedade

Além das prerrogativas previstas na regulamentação anterior, ao administrador foi conferida a

possibilidade de deliberar sobre a emissão de novas

cotas, observados os limites e condiç̃es estabelecidos no regulamento. (Art. 30, VIII)

$$
\text { nome do fundo. }
$$

As informações mínimas a serem divulgadas, semestralmente, pelas instituições administradoras compreendem: demonstrações financeiras; balanço patrimonial; demonstração do resultado; demonstração do fluxo de caixa; parecer do auditor independente; relatório do representante dos quotistas, quando eleito; relatório da instituição administradora.
O Capítulo VII sobre divulgação de informações sofreu alterações significativas. Os formulários foram todos revistos pela CVM, alguns foram eliminados e outros remodelados.
Inclusão do artigo art. 30, VIII que confere ao administrador a prerrogativa de deliberar sobre nova emissão de cotas.

Alteração do art. 39 a 41 para prever divulgação de informe mensal, trimestral e anual, resumo das deliberações da assembleia, proposta da

administração, pareceres e relatórios do representante de cotistas. Incluído rol exemplificativo para fatos relevantes. Lançamento do sistema Fundos Net para envio das informações periódicas e eventuais. Convênio firmado entre B3 e CVM para acompanhamento das informações periódicas e eventuais divulgadas pelos FII listados.

No FII a gestão é realizada pela administradora que deve obrigatoriamente ser instituição financeira. Já no FIP o papel do gestor é separado e definido, na SA a função é feita pelo Conselho de Administração e pela diretoria da companhia. No FII, portanto é responsabilidade da Administradora contratar os serviços especializados necessários a administração e gestão do fundo. As informações obrigatórias estão previstas em regulamento assim como no FIP, na SA existe a figura de relações com investidores.

O administrador recebeu importante incumbência na norma com a possibilidade de deliberar sobre nova emissão de cotas. Foram observadas alterações relevantes na divulgação de informações periódicas e eventuais pelo FII.

\section{Tabela 5}

\section{Conselho Fiscal}

\section{CONSELHO FERREIRA -}

FISCAL 2011

DADOS DA PESQUISA - 2017

\section{RESULTADO DA COMPARAÇÃO}

Composição

Não identificado.
O conselho fiscal de companhias abertas inspirou a criação do representante de cotistas no FII.
As alterações na ICVM 472 trouxeram esclarecimento de regras relacionadas à eleição, atividades e responsabilidades do representante de cotistas eleito para fiscalizar os empreendimentos ou investimentos do fundo, em defesa dos direitos e interesses dos cotistas.

UFAMBR, Manaus, v. 1, n.2, art. 1, pp. 01-27, julho-dezembro, 2019 http://www.periodicos.ufam.edu.br/ufambr 
Governança corporativa nos fundos de investimento imobiliário: mudanças após instrução CVM nº 571/2016

Atribuições

Relacionamento

ANÁLISE

FERREIRA - 2011

ANÁLISE

PESQUISA - 2017

Fonte: Dados da pesquisa

Tabela 6

\section{Auditoria Independente}

Não identificado

Não

identificado.
A Seção IV do CAPÍTULO V foi reformulada para inclusão de dispositivos sobre o representante de cotistas (percentuais para sua

eleição, atributos que deve ter para assumir os cargos, rol exaustivo de competências, obrigações e deveres).

A eleição de um representante permite a fiscalização e monitoramento do administrador pelos cotistas $\mathrm{e}$, indiretamente, $\mathrm{o}$ alinhamento de interesses entre eles. Pode ser remunerado ou não.
Inclusão de alterações nos artigos 25 e 26, inclusão do artigo 26-A, 26-B e 26-C.
No FII não existe a figura do Conselho Fiscal, que existe apenas na SA e mesmo assim de maneira pontual. O Conselho tem função fiscalizadora para estruturas mais complexas de ambiente de investimento.

Foram observadas alterações relevantes no esclarecimento de regras relacionadas à eleição, atividades e responsabilidades do representante de cotistas eleito.

\begin{tabular}{cc}
\hline AUDITORIA & FERREIRA - 2011 \\
INDEPENDENTE & As demonstrações financeiras do fundo \\
\hline Auditor Externo & $\begin{array}{c}\text { obedecerão às normas contábeis específicas } \\
\text { expedidas pela CVM e serão auditadas } \\
\text { anualmente, por auditor } \\
\text { independente registrado na CVM. }\end{array}$ \\
\hline
\end{tabular}

\section{Parecer da}

Auditoria

ANÁLISE

FERREIRA - 2011

\section{RESULTADO DA COMPARAÇÃO}

$\mathrm{O}$ auditor passa a ter a responsabilidade de descrever mais detalhadamente o relatório do auditor. Há maior interação com a

alta administração e os responsáveis pela governança.

O Relatório do Auditor, por iniciativa da International Federation of Accountants (IFAC), traz mudanças significativas no formato e conteúdo de maneira a torná-lo mais relevante para os investidores. O parecer do auditor independente deve estar disponível em trinta

$$
\text { dias antes da realização da assembleia geral ordinária. }
$$

Aumento da responsabilidade do auditor.

\section{Implemento do novo relatório do auditor}

No FII assim como no FIP e na SA existe a utilização obrigatória de auditoria independente para análise das demonstrações financeiras. 
Governança corporativa nos fundos de investimento imobiliário: mudanças após instrução CVM nº 571/2016

ANÁLISE

Apesar de não haver mudanças com relação ao escopo do trabalho de auditoria, será necessária uma comunicação mais constante e eficiente entre os auditores, a

administração e os órgãos de governança corporativa das entidades ao longo do trabalho e também empenho adicional na preparação e discussão de um relatório com PESQUISA - 2017 conteúdo específico ao invés de um conteúdo padronizado. Com essas mudanças, não será mais somente observada a opinião "aprovada/desaprovada", o Novo Relatório

do Auditor passa a ser aplicado para as auditorias do exercício a findar-se em 31 de dezembro de 2016 e trará conteúdo mais informativo aos interessados.

Nota: Dados da pesquisa

Tabela 7

\title{
Conduta e Conflito de Interesses
}

\begin{tabular}{|c|c|c|c|}
\hline $\begin{array}{l}\text { CONDUTA E } \\
\text { CONFLITO DE } \\
\text { INTERESSES }\end{array}$ & FERREIRA - 2011 & DADOS DA PESQUISA - 2017 & RESULTADO DA COMPARAÇÃO \\
\hline
\end{tabular}

\begin{abstract}
Situações de
Conflitos -

Identificação
\end{abstract}

Situações de

Conflitos -

Tratamento

Uso de Informações

São exemplos de situação de conflito de interesses operações com imóvel de propriedade do administrador,

ou integrante do patrimônio do fundo tendo como contraparte o administrador e a contratação, pelo fundo de pessoas ligadas ao administrador.

É vedado à instituição administradora realizar operações quando caracterizada situação de conflito de interesse entre o fundo e a instituição administradora, ou entre o fundo e o empreendedor. A decisão para indicar se a situação é ou não de conflito de interesses, é da assembleia geral.

A instituição líder deverá tomar todas as cautelas e agir com elevados padrões de diligência, para assegurar que: as informações prestadas pelo ofertante são verdadeiras, consistentes, corretas e suficientes, permitindo aos investidores uma tomada de decisão fundamentada a respeito da oferta; e as informações fornecidas ao mercado durante todo o prazo de distribuição, inclusive aquelas eventuais ou periódicas constantes da atualização
Hipóteses que configuram situações de conflito de interesse estão descritos no Art. 34. Inclusão de dispositivos sobre conflito de interesse para representantes de cotistas.

Previsto no Art. 35, inciso IX: ressalvada a hipótese de aprovação em assembleia geral nos termos do art. 34, realizar operações do fundo quando caracterizada situação de conflito de interesses entre o fundo e o administrador, gestor ou consultor especializado, entre o fundo e os cotistas mencionados no $\S 3^{\circ}$ deste art. 35 , entre o fundo e o representante de cotistas ou entre o fundo e o empreendedor.

As informações a respeito de informações em potencial conflito de interesse devem estar sempre disponíveis aos cotistas.
Inclusão da previsão de conflito de interesse entre fundo e o gestor, bem como do inciso $\mathrm{V}$ no $\S 1^{\circ}$ do art. 34, sobre a aquisição, pelo fundo, de valores mobiliários de emissão do administrador, gestor, consultor especializado ou pessoas a eles ligadas. Inclusão do Art. 26

Sem alterações

UFAMBR, Manaus, v. 1, n.2, art. 1, pp. 01-27, julho-dezembro, 2019 http://www.periodicos.ufam.edu.br/ufambr 
Governança corporativa nos fundos de investimento imobiliário: mudanças após instrução CVM nº 571/2016

do registro da companhia e as

constantes do estudo de viabilidade econômico-financeira

do empreendimento, são suficientes, permitindo aos

investidores a tomada de decisão fundamentada a respeito da oferta.

Mediação e

Arbitragem

ANÁLISE FERREIRA

$-2011$

ANÁLISE PESQUISA

- 2017
Não identificado.
Não identificado.
Sem alterações

No FII as operações envolvendo o administrador ou imóvel do administrador, assim como contratação de envolvidos com ele, são consideradas conflitos de interesses. Já no FIP são considerados conflitos de interesses, as operações que envolvem o administrador, o gestor ou membros do comitê, todos os papéis envolvidos no direcionamento dos negócios do fundo. Na SA o conceito é mais abrangente e mais detalhado, envolve qualquer tipo de atitude que o objetivo seja o benefício próprio e não do acionista, e para o acionista controlador existem vários exemplos que caracterizam conflitos de interesses. O tratamento no FII, quando caracterizado o conflito de interesses, é a proibição de a administradora realizar operações, já na SA, os envolvidos ficam impedidos de votar. No FII há preocupação

em fornecer informações suficientes para que o investidor tome decisões fundamentadas. Apenas para a SA é possível identificar a arbitragem para a solução de conflitos, no FII e no FIP situações de conflitos de interesses são raras, talvez por problemas na identificação, porém não há tratamento específico (via arbitragem) para os casos.

Nota: Dados da pesquisa

\subsection{Síntese da Documentação e Análise Comparada}

\section{Tabela 8}

\section{Propriedade}

PROPRIEDADE FERREIRA - 2011 DADOS DA PESQUISA - 2017 RESULTADO DA COMPARAÇÃO

\footnotetext{
Direito de Propriedade

A administradora é a proprietária fiduciária dos ativos que compõem o portfólio do fundo e responsável pela sua administração. Já os quotistas não têm qualquer direito real sobre os imóveis integrantes do fundo.

Direito a voto

A cada quota corresponde um voto nas assembleias do fundo.

O titular de cotas não poderá exercer qualquer direito real sobre os empreendimentos imobiliários integrantes do patrimônio do FUNDO.

A cada cota corresponderá um voto nas Assembleias Gerais. O cotista deve exercer o direito a voto no interesse do FUNDO.
}

Sem alteração

Inclusão de dispositivo que prevê que o voto do cotista deve ser no interesse do fundo, bem como da vedação do direito de voto ao cotista que estiver em situação de conflito de interesse.

UFAMBR, Manaus, v. 1, n.2, art. 1, pp. 01-27, julho-dezembro, 2019 http://www.periodicos.ufam.edu.br/ufambr 


\section{Regras de Assembleia} (convocação e pauta)

\section{Votação em}

Assembleia

Equidade no

Tratamento

ANÁLISE FERREIRA $-2011$
Compete à administradora convocar a assembleia, nesta convocação devem constar expressamente, todas as matérias a serem deliberadas.

A maioria dos assuntos depende da aprovação da maioria dos quotistas presentes, depende de aprovação dos quotistas que representem a maioria absoluta das quotas emitidas as

deliberações sobre: alterações do mercado em que as quotas estão admitidas; atos que caracterizem conflitos de interesses. Dependem da aprovação de $2 / 3$ das quotas emitidas, deliberações sobre: alteração de regulamento; fusão, incorporação e cisão e liquidação; alteração do objetivo e a política de investimentos previstos no regulamento.

O coordenador da emissão deve assegurar que $\mathrm{o}$ tratamento dos investidores seja justo e equitativo. Os quotistas do fundo podem ou não ter direito de preferência a subscrição de quotas, na mesma quantidade que possuírem na data de emissão de novas quotas.
A primeira convocação das Assembleias Gerais deverá ocorrer: com, no mínimo, 30 dias de antecedência no caso das Assembleias Gerais Ordinárias; e com, no mínimo, 15 dias de antecedência no caso das Assembleias Gerais Extraordinárias. Previsão de rol

taxativo com o mínimo de documentos a serem

disponibilizados para realização das assembleias.

Previsão de inclusão de assuntos na ordem do dia por cotistas ou representante de cotistas.

As deliberações da Assembleia Geral serão tomadas por maioria de votos dos cotistas presentes, ressalvado as deliberações que exigem quórum qualificado, que dependem da aprovação por maioria de votos dos cotistas presentes e que representem:

I. 25\%, no mínimo, das cotas emitidas, quando o fundo tiver mais de 100 cotistas; ou II. metade, no mínimo, das cotas emitidas, quando o fundo tiver até 100 cotistas.

De modo geral, nos regulamentos analisados, as cotas objeto da nova emissão asseguram a seus titulares direitos idênticos aos das

cotas existentes. Há casos em que o direito de preferência é concedido, porém a cessão desse direito é vedada. Um dos fundos não prevê o direito de preferência aos cotistas em caso de novas emissões
Inclusão dos dispositivos que tratam sobre antecedência para convocação das assembleias e sobre a disponibilização dos documentos mínimos necessários para sua realização. Previsão de inclusão de assuntos na ordem do dia.

A partir da análise da documentação selecionada para o presente estudo, o item Propriedade reflete as informações da Regulamentação. Os quotistas têm posse indireta, não exercendo qualquer direito sobre os imóveis e ativos pertencentes ao fundo ou a companhia (no caso da SA), e a administração é responsabilidade da administradora (para FII ou FIP) ou do Conselho de Administração (no caso da SA). Cada quota concede direito a um voto e no caso da SA apenas as ações ordinárias votam. Sobre as regras de convocação e pauta, vale ressaltar que para a SA, todos os assuntos tratados em assembleia foram previamente discutidos pelo Conselho de Administração; o que indica que o direcionamento da companhia é traçado pelo Conselho e apenas aprovado ou não pela assembleia. Os quóruns de aprovação também refletem a Regulamentação, observado que se identificou a possibilidade de alterações de quóruns de aprovação pela CVM, para SA, desde que comprovada a pulverização das ações no mercado. Em ambos os casos (FII e SA) pode ou não existir o direito de preferência para a subscrição de novas quotas ou ações.

UFAMBR, Manaus, v. 1, n.2, art. 1, pp. 01-27, julho-dezembro, 2019 http://www.periodicos.ufam.edu.br/ufambr 
Governança corporativa nos fundos de investimento imobiliário: mudanças após instrução CVM nº 571/2016

ANÁLISE PESQUISA

$-2017$

Nota: Dados da pesquisa

Tabela 9

\section{Conselho de Administração}

\section{CONSELHO DE}

ADMINISTRAÇÃO

Composição do
Conselho

Relacionamento

\section{Atribuições do \\ Conselho - \\ Estratégia de}

Investimento
Não possui a figura do Conselho de Administração. Portanto neste item estão identificadas atividades que seriam realizadas pelo Conselho de Administração, porém no FII são realizadas por outros

integrantes como o consultor de investimentos ou o representante dos quotistas.

É dever do administrador controlar e supervisionar as atividades inerentes a gestão dos ativos do fundo,

fiscalizando os serviços prestados por terceiros contratados e o andamento dos empreendimentos imobiliários.

Há com único empreendimento, único segmento e genéricos portanto desta forma há indicação das diversas estratégias de investimento encontradas. Nos regulamentos deve constar indicação do objeto do fundo, ou segmento e tipo de imóveis

ou ativos, nos quais os recursos serão investidos. Consta ainda indicação se os empreendimentos estarão prontos e se para o FII é permitida a aquisição de imóveis em construção. O FII pode ainda ser composto de quotas de FIP, bem como quotas de outros FII, letras hipotecárias ("LH"); letras de crédito imobiliário ("LCI"); certificados de recebíveis imobiliários ("CRI"); ações ou quotas de sociedades cujo único propósito se enquadre entre as atividades permitidas aos FII.

DADOS DA PESQUISA - 2017

RESULTADO DA COMPARAÇÃO

Nos regulamentos devem dispor sobre a possibilidade de aquisição de imóveis gravados com ônus reais bem como sobre sua delimitação geográfica, se aplicável. Ademais, deve haver descrição do objetivo fundamental dos investimentos (ganho de capital, obtenção de renda ou ambos)
Regulamento foram atualizados para prever possibilidade do investimento em letras imobiliárias garantidas (incluída pela nova regulamentação), para dispor sobre possibilidade de aquisição de imóveis com ônus reais, localização geográfica dos imóveis e para descrição do objetivo fundamental dos investimentos 
Governança corporativa nos fundos de investimento imobiliário: mudanças após instrução CVM nº 571/2016

Atribuições do Conselho - Captação de Recursos

ANÁLISE FERREIRA $-2011$

\section{ANÁLISE PESQUISA} $-2017$

Conforme regulamento, fica dispensado a realização de assembleia de quotistas para deliberar sobre futuras emissões de quotas, desde que dentro de um limite de quotas fixado, se necessária a emissão de quotas superior a este limite, será

necessária a aprovação em assembleia. Na ocasião do anúncio, deve constar a indicação de quantidade mínima de subscrição, com possibilidade de cancelamento das quotas não subscritas.
Embora a nova regulamentação tenha permitido a emissão de novas cotas a critério do administrador (desde que previsto previamente no regulamento do fundo - capital autorizado), situação na qual é o direito de preferência deve ser concedido aos cotistas, obrigatoriamente, conforme o disposto na nova regulamentação, nenhum dos regulamentos analisados contem tal previsão.
Permissão para emissão de novas cotas a critério do administrador, sem aprovação da assembleia, desde que haja previa previsão em regulamento.

A figura do Conselho de Administração não existe no FII. Partes das funções do Conselho de Administração, como o direcionamento da estratégia do fundo, são realizadas pelo próprio consultor de investimentos, pode ainda existir a figura do representante dos quotistas, apenas com poder de influência, mas não de deliberação. No FIP existe o Comitê de Investimentos, o fundo participa do processo decisório das empresas investidas. No FII após as recentes alterações na legislação, a gama de ativos que podem compor os portfólios aumentou, porém a estratégia do fundo é definida em seu regulamento e a maioria dos FII pesquisados está dividida por classes de investimento e até de tipos de ativos, alguns só de imóveis outros só de ativos financeiros (quotas de outros fundos, CRI), mesmo dentro do tipo de ativo, ainda identifica-se, um direcionamento estratégico por tipo de imóvel ou por região. A captação de recursos do FII está prevista em regulamento, pode ser ampliada a partir de votação em assembleia, no FIP o investimento está pré-determinado com período de início e fim. Na SA as emissões de ações podem ocorrer ao longo do tempo.

A figura do representante foi objeto de aprimoramentos na nova instrução, recebendo uma série de esclarecimentos relacionados a sua função. Porem não houve alteração, sua função é fiscalizadora e não de deliberação. A gama de ativos que podem compor o portfolio do FII novamente aumentou. Embora a nova regulamentação tenha permitido a emissão de novas cotas a critério do administrador (desde que previsto previamente no regulamento do fundo - capital autorizado), situação na qual é o direito de preferência deve ser concedido aos cotistas, obrigatoriamente, conforme o disposto na nova regulamentação, nenhum dos regulamentos analisados contem tal previsão.

Fonte: Dados da pesquisa

\section{Tabela 10}

\section{Regras de Distribuição e Dispersão}

REGRAS DE

DISTRIBUIÇÃO E DISPERSÃO
FERREIRA - 2011

DADOS DA PESQUISA - 2017
RESULTADO DA COMPARAÇÃO

Liquidez

Não identificado.

UFAMBR, Manaus, v. 1, n.2, art. 1, pp. 01-27, julho-dezembro, 2019 http://www.periodicos.ufam.edu.br/ufambr 
Governança corporativa nos fundos de investimento imobiliário: mudanças após instrução CVM nº 571/2016

Há indicação de que as quotas são colocadas no regime de melhores esforços, não sendo utilizada a sistemática de reserva. Não há restrição quanto ao limite de quotas que podem ser subscritas por um único quotista, mas para que o fundo seja isento de tributação sobre a receita operacional, o incorporador sócio ou construtor do empreendimento imobiliário investidos não pode adquirir mais de

Dispersão

$$
25 \% \text { das quotas emitidas pelo fundo. }
$$

ANÁLISE FERREIRA 2011

ANÁLISE PESQUISA 2017
Apenas na SA consta indicação de percentual mínimo de ações que devem ser mantidas em circulação. No FII há preocupação com relação ao máximo de quotas subscritas por um único quotista, porque a partir de determinada quantidade perde-se o benefício da isenção.

Nota: Dados da pesquisa

Com a edição da nova regulamentação, não foram observados novos mecanismos que propiciem a dispersão das cotas. Para o FII, com relação a esta questão, o único impedimento que se observa em relação à dispersão é a possibilidade de perda do benefício fiscal.

\section{Tabela 11}

\section{Gestão}

\section{GESTÃO}

Composição da Gestão Na maioria, dos FII analisados, só há a administradora, em alguns casos há o gestor.

A administradora poderá, sem prévia anuência dos quotistas praticar os seguintes atos necessários à consecução dos objetivos do fundo: adquirir ou alienar imóveis para o patrimônio do fundo de acordo com os critérios estabelecidos no regulamento, caso não se enquadre nos critérios constantes do regulamento, esta deverá ser previamente aprovada pelos quotistas em Assembleia. A administradora deverá prover o fundo com os serviços necessários ao adequado funcionamento. Na maioria dos casos e como previsto na regulamentação, a figura do gestor não é claramente definida. Para algumas estruturas de FII,
dependentemente da regulamentação a figura do gestor é bem definida através

Funções da de seus documentos (prospecto, regulamento). O gestor deve: identificar, selecionar, avaliar, adquirir, acompanhar e alienar, sem necessidade de aprovação em assembleia geral, de acordo com a política de investimento prevista no regulamento; todas as operações necessárias à execução da política de investimento, exercendo; controlar e supervisionar as atividades inerentes à gestão dos ativos do fundo.

\section{DADOS DA PESQUISA - 2017}

Sem alteração

Sem alteração
A prerrogativa acrescida às funções da administradora, sobre deliberar acerca de nova emissão de cotas, sem prévia anuência da assembleia geral de cotistas, prevista no artigo art. 30, VIII, foi refletida somente em um dos regulamentos analisados.
Atualização de um dos regulamentos para prever a possibilidade do administrador emitir cotas nos termos do artigo art. 30, VIII.

UFAMBR, Manaus, v. 1, n.2, art. 1, pp. 01-27, julho-dezembro, 2019 http://www.periodicos.ufam.edu.br/ufambr 
Governança corporativa nos fundos de investimento imobiliário: mudanças após instrução CVM nº 571/2016

Informações

A administradora tem o dever de dar cumprimento aos deveres de informação previstos no regulamento e deve: divulgar, ampla e imediatamente, qualquer ato ou fato relevante relativo ao fundo ou as suas operações.
Algum dos FII possui site específico para divulgação das informações do fundo (e não no site do administrador junto com outras informações), utilização do correio eletrônico para divulgação das informações, descontinuando o uso de correspondência física. Alguns regulamentos replicam o

Capítulo VII da ICVM 472 sobre obrigatoriedade da

divulgação de informações. Alguns fundos possuem departamento específico para atendimento aos investidores e política de divulgação de fato relevante. Entrou em vigor sistema Fundos Net, o qual divulga as informações periódicas e eventuais dos FII.
Site próprio FII, uso de correio eletrônico, atendimento aos cotistas (departamento de relação com investidores), sistema Fundos Net, política de

divulgação de fato relevante.

A administradora tem a responsabilidade de prover o FII com os serviços de gestão, seja contratado ou exercido por ela mesma. As operações permitidas são as previstas em regulamento, casos contrários dependem da aprovação da assembleia. No FIP o gestor cumpre as determinações do Comitê de Investimentos e na SA a gestão é feita pela

diretoria e pelo Conselho. Nos regulamentos do FII e FIP e no estatuto da SA, estão definidas informações e periodicidade com que devem ser divulgadas. No caso específico da SA, há mais critérios de informações que devem ser divulgadas devido às regras do Novo Mercado, que a companhia pode ou não estar submetida.

ANÁLISE 2011

ANÁLISE

PESQUISA 2017

Observou-se muita evolução com relação às funções da administradora e divulgação de informações. O administrador ganhou a prerrogativa de deliberar sobre nova emissão de cotas, sem prévia anuência da assembleia geral de cotistas, prevista no artigo art. 30, VIII. Com relação à divulgação de informações, além da reformulação promovida pela nova regulamentação, alguns FII já possuem site próprio para divulgação de informações, utilizam exclusivamente o correio eletrônico para divulgar as informações, possuem departamento de relação com investidores e política de divulgação de fato relevante. Outro ponto relevante foi o advento do sistema Fundos Net, de propriedade da CVM e operado pela B3, que recebe as informações periódicas e eventuais dos fundos.

\section{Nota: Dados da pesquisa}

\section{Tabela 12}

\section{Conselho Fiscal}

CONSELHO FISCAL FERREIRA 2011

DADOS DA PESQUISA - 2017

RESULTADO DA COMPARAÇÃO

A maior parte dos FII analisados, prevê a eleição de até 1 representante de cotista. Somente um deles permite a eleição de até 3 representante de cotista. Um dos FII prevê que os representantes Composição Não identificado.

dos cotistas não receberão qualquer tipo de remuneração pelo exercício de suas funções, salvo se aprovado o contrário em Assembleia Geral de Cotistas que o eleger. Outros FII preveem que a remuneração dos representantes e o valor máximo das despesas incorridas por ele serão definidos pela mesma assembleia
Estipulação, pelo administrador, quando da adaptação do regulamento à nova instrução, do número máximo de representantes de cotistas do fundo Os regulamentos que não estipularam número máximo, deixaram a critério de a assembleia geral estipular tais condições.

UFAMBR, Manaus, v. 1, n.2, art. 1, pp. 01-27, julho-dezembro, 2019 http://www.periodicos.ufam.edu.br/ufambr 
Governança corporativa nos fundos de investimento imobiliário: mudanças após instrução CVM nº 571/2016

que os eleger.

Atribuições

Não identificado.

Enh razão do esclarecimento das atribuições dada pela nova

regulamentação, os regulamentos dos FII refletem essas

informações em capítulos próprios. Rol exaustivo de atribuições, estando entre eles a elaboração de relatório com conteúdo mínimo.

O representante se relaciona com a administradora para obter informações e esclarecimentos desde que relativos à sua função fiscalizadora. A administradora é obrigada, por meio de Relacionamento Não identificado. $\begin{gathered}\text { comunicação por escrito, a colocar à disposição dos representantes } \\ \text { dos cotistas, em no máximo, } 90 \text { (noventa dias) dias a contar do } \\ \text { encerramento do exercício }\end{gathered}$

formulário. O representante se relaciona com os cotistas,

representando-os, devendo responder seus os pedidos de informações.

Apenas na SA aparece a figura do Conselho Fiscal, que pode ou não existir.

O representante de cotista foi criado no FII com inspiração no conselho fiscal das companhias. A nova regulamentacão esclareceu diversos pontos com relação ao seu papel, tal como sua forma de eleição, seu mandato, requisitos para candidatura, remuneração, atribuição, deveres, obrigações e responsabilidade. Os regulamentos dos fundos analisados foram adaptados a nova regulamentação. Alguns deles, em razão do lapso temporal, deixaram algumas das definições (número de representante, remuneração e valor máximo de despesas) a critério da assembleia geral de cotistas.

Nota: Dados da pesquisa

\section{Tabela 13}

\section{Auditoria Independente}

AUDITORIA

INDEPENDENTE

Auditor Externo
FERREIRA - 2011

A contratação de auditoria independente será realizada pela administradora, através de assembleia geral de quotistas que escolherá a empresa para prestar os serviços.
DADOS DA PESQUISA - 2017

Alguns dos regulamentos analisados incluem o nome da empresa de auditoria contratada pela administradora. Outros deixam tal clausula de forma genérica, sem mencionar o prestador.

\section{RESULTADO DA COMPARAÇÃO}

A administradora é responsável por contratar a empresa de auditoria. Em alguns casos, submete a proposta de contratação à assembleia geral de cotistas. Há FII que especificam no regulamento a empresa de auditoria contratada.

UFAMBR, Manaus, v. 1, n.2, art. 1, pp. 01-27, julho-dezembro, 2019 http://www.periodicos.ufam.edu.br/ufambr 
Governança corporativa nos fundos de investimento imobiliário: mudanças após instrução CVM nº 571/2016

\section{Parecer da Auditoria}

ANÁLISE FERREIRA

$-2011$

ANÁLISE PESQUISA - 2017
O parecer da auditoria é apresentado em

assembleia geral, aos quotistas para deliberação.
O parecer do auditor independente deve ser disponibilizado juntamente com as demonstrações financeiras em até 90 dias do encerramento do exercício social e/ou trinta dias antes da realização da assembleia geral

$\mathrm{Na}$ antiga regulamentação o parecer do auditor era tratado como relatório.

$$
\text { ordinária. }
$$

No FII, FIP e SA, há indicação de auditoria independente para análise das demonstrações contábeis.

Nota: Dados da pesquisa

Tabela 14

Conduta e Conflito de Interesses

$\begin{array}{lll}\text { CONDUTA E } & & \\ \text { CONFLITO DE } & \text { FERREIRA - } 2011 \quad \text { DADOS DA PESQUISA - } 2017\end{array}$

Algumas situações são indicadas como ações que caracterizam conflito de interesses: aquisição,

locação, arrendamento ou exploração do direito de superfície do fundo, de imóvel de propriedade da

administradora; de imóvel integrante do

Identificação

patrimônio do fundo tendo como contraparte a administradora; de imóvel de propriedade de devedores da administradora; contratação pelo

fundo, de pessoas ligadas a administradora para

Adaptação do regulamento a nova regulamentação. Inclusão de dispositivos sobre conflito de interesse para representantes de cotistas.
Adaptação do regulamento a nova regulamentação. Alguns replicam as clausulas dispostas na regulamentação sobre conflito de interesse e pessoas ligadas e outros fazem remissão à lei. 
Governança corporativa nos fundos de investimento imobiliário: mudanças após instrução CVM nº 571/2016

\section{Situações de}

Conflitos -

Tratamento

\section{Uso de Informações}

\section{Mediação e}

Arbitragem

ANÁLISE FERREIRA - 2011

ANÁLISE PESQUISA - 2017
Os atos que caracterizem conflito de interesses entre o fundo e o administrador dependem de aprovação prévia da assembleia geral.

Sem previsão

Para a solução amigável de conflitos relacionados ao regulamento,

reclamações ou pedidos de esclarecimentos poderão ser

direcionados ao atendimento comercial.
Sem alteração

Sem previsão
Nenhum regulamento apresentou tratamento diferenciado.
Há clausulas estipulando a resolução, por meio de arbitragem, de toda e qualquer disputa ou controvérsia que possa surgir entre administradora e cotistas. Outros estipulam o foro ou sede do cotista da solução amigável de conflitos. Se não for solucionado o conflito, a ouvidoria do grupo do administrador pode ser contatada.
Inclusão de cláusula de arbitragem e direcionamento para ouvidoria.

No FII, operações que envolvam a administradora ou ativos pertencentes a administradora é indicada como situações de conflitos de interesses. No FIP não é permitido investir em companhias em que participem a administradora ou membro do comitê. Já na SA, existe um Código de Conduta que indica os padrões de conduta e transparência a serem adotados. Para tratamento, os casos que configurem conflitos de interesses serão aprovados pela assembleia geral; na SA há um comitê de ética para discutir as situações que estejam em desacordo com o código de conduta. Há indicações de que as informações sigilosas não devem ser utilizadas para benefício dos que têm acesso privilegiado, antes de divulgadas ao mercado. Na documentação o FII deve solucionar conflitos de maneira amigável, já no FIP e na SA há indicação de que deve ser utilizada a Câmara de Arbitragem.

Nota: dados da pesquisa conflitos. 
A conclusão da Análise Comparada, a partir da Regulamentação e da Documentação dos FII, identificou que no item Propriedade, houve alterações referentes ao direito e vedações ao voto dos cotistas, das regras de assembleia (prazos de convocação, disponibilização de documentos e possibilidade de assuntos na ordem do dia, quóruns diferenciados para assuntos mais sensíveis, baseado na representatividade das cotas emitidas e do número de cotistas). Observou-se também o incremento do rol de matérias que exigem quóruns qualificados e houve a inclusão de dispositivo que proporciona equidade no tratamento dos cotistas. Todos os regulamentos analisados já foram adaptados em relação a estes quesitos.

Sobre o assunto, a CVM, no relatório de análise da audiência pública de alteração da instrução n' 472/2008, esclarece que:

A CVM concorda com a proposta da BM\&FBOVESPA para a extensão do prazo de convocação de assembleias gerais de 10 para 15 dias úteis de antecedência. Em linha com a regra atualmente vigente para as sociedades por ações, a CVM entende que esse prazo atende simultaneamente a necessidade dos investidores de tempo hábil para se organizar e analisar a ordem do dia das assembleias gerais, bem como a necessidade dos administradores dos fundos de aprovar de maneira célere determinadas operações (CVM, 2015).

Para a CVM, o estabelecimento de um quórum qualificado de deliberação tem como intuito assegurar que matérias relevantes ou sensíveis sejam apreciadas por uma parcela significativa do universo de cotistas. Dentre as matérias sujeitas a tal quórum, a CVM entende que devam constar todas aquelas que digam respeito às regras gerais de funcionamento do fundo, às suas características essenciais e aos direitos dos cotistas (CVM, 2015).

Para o item Conselho de Administração, verificou-se que a rigidez para realização de alterações no regulamento, como ocorria no passado, foi flexibilizada e recebeu novos critérios na nova instrução. Disto resultou em novas oportunidades para captação de recursos, seja por deliberação da assembleia, cujos quóruns foram ajustados para facilitar as aprovações, seja pelas emissões aprovadas a critério do administrador, a exemplo do que ocorre com as companhias com o capital autorizado. Nenhum dos regulamentos analisados incluiu tal previsão até o momento.

Cabe esclarecer que a proposta contida na Minuta em relação ao art. 15, VIII, da Instrução CVM $n^{\circ} 472$, de 2008, foi inspirada nas regras atualmente vigentes para as sociedades por ações - em especial, no art. 168, § 1 ${ }^{\circ}$, "b", da Lei $\mathrm{n}^{\circ} 6.404$, de 1976, que permite ao estatuto social dispor sobre a competência do conselho de administração para aprovar novas emissões de ações, dentro do limite do capital autorizado e independentemente de reforma estatutária (CVM, 2015).

No item Regras de Distribuição e Dispersão, a questão da concentração das cotas do fundo nas mãos de poucos cotistas, apresentada por Ferreira (2011), após a alteração promovida na Instrução CVM no 472/2008 permaneceu. Não houve alterações na legislação para inibir tais práticas, sendo que os motivos para tanto podem estar associados à própria dinâmica do mercado de capitais e das características do produto FII.

No item Gestão, o administrador, após a edição da nova regulamentação, recebeu importante incumbência consistente na possibilidade de deliberar sobre nova emissão de cotas. Foram observadas alterações relevantes na divulgação de informações periódicas e eventuais pelo FII. Além disso, sobre o tema Divulgação de Informações, passou-se a exigir, no novo informe anual, o preenchimento de dados sobre a política de divulgação de fatos relevantes e 
sobre a política de negociação das cotas. Houve também o lançamento do sistema Fundos Net, plataforma que divulga as informações periódicas e eventuais dos FII e foi firmado convenio entre B3 e CVM para a fiscalização da divulgação dessas informações pelos administradores. Pontua a CVM, sobre estas questões que:

O envio de qualquer informação aos cotistas (por exemplo, por meio eletrônico) deverá ocorrer simultaneamente à divulgação da mesma informação na página do administrador na rede mundial de computadores e ao seu envio à CVM e à administradora do mercado em que as cotas sejam admitidas à negociação, por meio do sistema de envio de documentos disponível na página da CVM na rede mundial de computadores (CVM, 2015).

No item Conselho Fiscal, foram observadas alterações relevantes no esclarecimento de regras relacionadas à eleição, atividades e responsabilidades do representante de cotistas eleito. Os regulamentos dos fundos analisados foram adaptados à nova regulamentação. Alguns deles, em razão do lapso temporal, deixaram algumas das definições (número de representante, remuneração e valor máximo de despesas) a critério da próxima assembleia geral ordinária de cotistas.

Conforme já mencionado pela CVM em mais de uma oportunidade, a figura do representante de cotistas foi inspirada no conselho fiscal das sociedades por ações e inserida na regulamentação para permitir a efetiva fiscalização e monitoramento do administrador por um agente que atuasse em nome e na defesa dos interesses dos cotistas (CVM, 2015).

No item Auditoria Independente, apesar de não ter tido mudanças com relação ao escopo do trabalho de auditoria, para elaboração do Novo Relatório do Auditor, será necessária uma comunicação mais constante e eficiente entre os auditores, a administração e os órgãos de governança corporativa das entidades. $\mathrm{O}$ administrador passou a ser responsável por indicar, no sistema Fundos Net, o tipo de parecer elaborado pelo auditor quando da divulgação das demonstrações financeiras.

No item Conduta e Conflitos de Interesses, o leque de situações que caracterizam conflito de interesses no FII foi incrementado. Verificou-se a inclusão, nos regulamentos analisados, de cláusula de arbitragem e direcionamento para departamento de auditoria visando solucionar conflitos observados entre o fundo e os cotistas.

O mecanismo proposto pela atual Instrução CVM no 472, de 2008, e ainda corroborado pela CVM, é o de que os cotistas reunidos em assembleia geral, de forma independente, possam avaliar casuisticamente a existência de conflito de interessem em operações entre o fundo e o administrador ou pessoas a ele ligadas. Além da independência, o investimento no fundo e o acompanhamento de suas atividades contribuem para que seja mais adequada a análise das operações pelos cotistas do que pela CVM (CVM, 2015).

Diante do exposto, resta evidente que alterações foram realizadas e implementadas nos FII desde 2011.

\section{CONCLUSÃO}

O presente estudo replicou pesquisa desenvolvida por Ferreira (2011), a fim de verificar o aprimoramento da governança corporativa pós-edição da Instrução CVM n ${ }^{\circ}$ 571/2016, por meio da análise da regulamentação e da documentação de FII selecionados. 
Os resultados encontrados na presente pesquisa diferem dos obtidos no trabalho de Ferrari (2016), pois foram constatadas diversas evidências de alterações na regulamentação desde 2011, que foram incorporadas e impactam positivamente na governança corporativa dos FII.

Merece destaque as novas responsabilidades e atribuições do administrador, o ativismo dos cotistas na participação das decisões do rumo do fundo e o papel das novas tecnologias digitais na disseminação de informações, as quais facilitam o acompanhamento de sua divulgação, de modo a garantir o acesso dos investidores a informações adequadas, possibilitando a tomada de decisão de forma consciente e fortalecendo a confiança neste mercado.

Não obstante, foram identificados pontos para discussões futuras que devem ser avaliados, sobretudo no caso da superveniência de novas regulamentações a fim de verificar a evolução da governança nos FII.

Posto isto, pode-se esperar mudanças no perfil da indústria de fundos, tendo em vista o incremento da transparência das informações motivada pela nova norma, que teve como objetivo principal fortalecer a proteção aos investidores.

\section{REFERÊNCIAS}

Brito. N. \& Alencar, C. T. (2016, setembro) Análise da Qualidade das Informações Disponibilizadas pelos Gestores de Fundos de Investimento Imobiliário no Brasil. Anais da Conferência Internacional da Latin American Real State Society, São Paulo, SP, Brasil Recuperado de: http://lares.org.br/16a-conferencia-internacionallares/artigos/BRITO_ANALISE_ARTIGO.pdf.

CVM. Comissão de Valores Mobiliários. (2015). Relatório de Análise. Audiência Pública SDM n $n^{\circ}$ 07/14 - Processo CVM no RJ 2012-6197. 2015. Recuperado de: http://www.cvm.gov.br/audiencias_publicas/ap_sdm/2014/sdm0714.html.

Ferreira, F. M. (2011) Fundos de investimento imobiliário - governança corporativa. Dissertação de (Mestrado em Engenharia) Escola Politécnica, Universidade de São Paulo. São Paulo, Brasil

Ferrari, C. E. P. (2016) Vida Nova Instrução 571 da CVM intensifica a transparência e melhora governança dos FIIs. Recuperado de: https://capitalaberto.com.br/extra/fiis/.

Gil, A. C. (2010). Como Elaborar Projetos de Pesquisa. (5a ed.). São Paulo: Atlas.

Guia CVM do Investidor Fundos de Investimento Imobiliário (2015). Recuperado de: http://www.investidor.gov.br/portaldoinvestidor/export/sites/portaldoinvestidor/publicaca o/serie_guias/guia_CVM_FII_2ed.pdf.

Instituto Brasileiro de Governança Corporativa. (2017). Governança Corporativa. Recuperado de: http://www.ibgc.org.br/index.php/governanca/governanca-corporativa.

Instrução CVM n 472, de 31 de outubro de 2008. Dispõe sobre a constituição, a administração, o funcionamento, a oferta pública de distribuição de cotas e a divulgação de informações dos Fundos de Investimento Imobiliário - FII. Recuperado de: http://www.cvm.gov.br/legislacao/inst/inst472.html. 
Instrução CVM n 571, de 25 de novembro de 2015. Altera dispositivos da Instrução CVM no 472, de 31 de outubro de 2008, e da Instrução CVM n 400, de 29 de dezembro de 2003. Recuperado de: http://www.cvm.gov.br/legislacao/inst/inst571.html.

Moraes, A. V. (2016) Diversificação dos fundos de investimento imobiliário brasileiros. Dissertação de (Mestrado Profissional em Administração) Fundação Escola de Comércio Álvares Penteado - FECAP, São Paulo, Brasil.

Okazuka, M., Jr. (2015). Fundos de Investimento Imobiliário e suas características de hedge contra a inflação no Brasil. (Dissertação de mestrado). Fundação Getúlio Vargas - FGV, São Paulo, SP, Brasil.

Sato, G. E. (2008) A Atratividade do investimento no mercado de edifícios de escritórios da cidade de São Paulo por meio de Fundos de Investimento em Participações sob a ótica do investidor estrangeiro. Dissertação de (Mestrado em Engenharia) Escola Politécnica, Universidade de São Paulo, São Paulo, Brasil.

Silveira, A. M. (2002) Governança Corporativa, desempenho e valor da empresa no Brasil. Dissertação de (Mestrado em Administração) Faculdade de Economia, Administração e Contabilidade, Universidade de São Paulo, São Paulo, Brasil.

Steffen, M. A. (2015) Rentabilidade dos fundos de investimento imobiliários: uma análise da influência da Bolsa de Valores, dos juros e de fatores específicos do mercado. Dissertação de (Mestrado em Administração) Faculdade de Economia, Administração e Contabilidade, Universidade de São Paulo, São Paulo, Brasil. 